\title{
Sustainable Suburban Environment and Service for Happier Households
}

\author{
Boo Ho Voon', Liping Wang', Ai Kiat Teo ${ }^{3}$ \\ 1 Universiti Teknologi MARA, Samarahan, Malaysia, \\ ${ }^{2}$ Zhejiang Agricultural Business College, China, ${ }^{3}$ SMK DPHA Gapor, Kuching, Malaysia \\ bhvoon@uitm.edu.my, 118113112@qq.com, aikiat67@yahoo.com \\ Tel of 1st Author: 019-4390228
}

\begin{abstract}
Many emerging economies have allocated a significant amount of resources for sustainable suburbanization and development initiatives to serve and care for the targeted communities for happier households. The governments, private enterprises, and NGOs have been working together for sustainable suburban socio-economic development. Their sustainability practices and good quality service have helped to achieve the desired development outcomes for a better quality of life for the stakeholders. This paper aims to share the case study of Batu Kawa Suburb (Kuching, Sarawak) and the related lessons from Shaoxing (Zhejiang, China) to understand sustainable suburbanization environment and service for sustainability.
\end{abstract}

Keywords: Sustainable suburban environment; Service.

eISSN: 2398-4287@ 2021. The Authors. Published for AMER ABRA CE-Bs by e-International Publishing House, Ltd., UK. This is an open access article under the CC BYNC-ND license (http://creativecommons.org/licenses/by-nc-nd/4.0/). Peer-review under responsibility of AMER (Association of Malaysian Environment-Behaviour Researchers), ABRA (Association of Behavioural Researchers on Asians/Africans/Arabians) and cE-Bs (Centre for Environment-Behaviour Studies), Faculty of Architecture, Planning \& Surveying, Universiti Teknologi MARA, Malaysia. DOI: https://doi.org/10.21834/ebpj.v6i17.2886

\subsection{Introduction}

Strategic suburbanization is imperative to solve or resolve the socio-economic challenges of rapid urbanization. Having a well-planned and sustainable suburban socio-economic development is essential (e.g., Fan \& Xue, 2018; Freimane, 2021; Péter \& Csaba, 2021). Achieving and sustaining a livable and vibrant suburban environment is among the key focus areas of many governments and local authorities for sustainability (Hezri, 2004). The state and local governments as well as other public and private organizations have consistently and continuously recognized the need for sustainable socio-economic development in suburbanization. Their sustainability practices and good quality service help to achieve the desired development outcomes for a better quality of life for the various stakeholders. The socio-economic development service includes public services and utilities, commercial and retailing services, agriculture and marketing, infrastructure and utilities, tourism and hospitality, education and human resources, safety and security, spirituality and morality, prospering towards high income and better quality of life of the suburban households for sustainability. This paper aims to present the exploratory research findings from Batu Kawa (Sarawak, Malaysia) and the related personal experiences from Shaoxing (Zhejiang, China) about sustainable suburban development.

eISSN: 2398-4287C 2021. The Authors. Published for AMER ABRA cE-Bs by e-International Publishing House, Ltd., UK. This is an open access article under the CC BYNC-ND license (http://creativecommons.org/licenses/by-nc-nd/4.0/). Peer-review under responsibility of AMER (Association of Malaysian Environment-Behaviour Researchers), ABRA (Association of Behavioural Researchers on Asians/Africans/Arabians) and cE-Bs (Centre for Environment-Behaviour Studies), Faculty of Architecture, Planning \& Surveying, Universiti Teknologi MARA, Malaysia.

DOI: https://doi.org/10.21834/ebpj.v6i17.2886 


\subsection{Literature Review}

Sustainable development is promoted and practiced by many nations, cities, towns, and villages worldwide. The citizens, communities, folks, and related stakeholders enjoy the fruits of a balanced and equitable socio-economic development implemented by the responsible governments, authorities, and participating agents. The Sustainable Development Goals (SDGs) established by United Nations serve as good guidelines. Table 1 shows the 17 SDGs for sustainable development. The 102 items aim to take care of the natural environment and resources, cost-effectiveness, and social inclusion for sustainability. There are items (16 items) that are more suitable for national and international performance measurement. The remaining 86 items can be potentially relevant and useful for sustainable suburban socio-economic development measurement and improvement purposes.

Table 1. The Sustainable Development Goals (SDGs)

\begin{tabular}{ll}
\hline SDGs & Items (suburb) \\
\hline 1, No Poverty & 2 \\
2. Zero Hunger & $8(7)$ \\
3. Good Health and Well-being & 14 \\
4. Quality Education & 3 \\
5. Gender Equity & 4 \\
6. Clean water and Sanitation & 5 \\
7. Affordable and Clean Energy & 3 \\
8. Decent Work and Economic Growth & 6 \\
9. Industry, Innovations, and Infrastructure & $6(4)$ \\
10. Reduced Inequality & 2 \\
11. Sustainable Cities and Communities & 4 \\
12. Responsible Consumption and Production & $6(4)$ \\
13. Climate Action & $3(1)$ \\
14. Life Below Water & $6(2)$ \\
15. Life on Land & $5(3)$ \\
16. Peace, Justice, and Strong Institutions & $10(9)$ \\
17. Partnership for the Goals & $5(3)$ \\
& $102(86)$ \\
\hline (Source:) Adapted from Sachs et al. (2021). Sustainable Development Report 2021
\end{tabular}

In suburbanization, the natural-economic-social dimensions of sustainability need to be consistently emphasized and implemented accordingly to benefit the households. Suburban residents are more mobile and need a good public transportation system. The more efficient commutes are a significant quality of life factor for the economically poorer residents (Jang, Yan \& Lopez, 2021). Rational individuals and households are expecting higher income, good health and happiness, and overall better quality of life. Concerted efforts and continual cooperation from all parties are essential for sustainability (Wang et al., 2019). Hence, representative voices and actions for effective implementations of strategies and programs are necessary to co-create and achieve the shared values for sustainability (Hezri, 2004). The physical designs in the suburban environment can add socio-economic value to the residents. Design can create happy and satisfied societies (Freimane, 2021).

The intended socio-economic development service has comprehensive domains. The evolving changes and behaviors of the various stakeholders are acknowledged. Effective communication with the target suburban community is essential. Having the right and valid information is essential because service is intangible, variable, and perishable. The quality of service, resident satisfaction, and behavioral intentions are closely related (Voon, 2012). Moreover, the sustainable service is most probably systemic and involves many processes and systems (Chen et al., 2020; Vargo, Wieland \& Akaka, 2016; Voon, 2018, Zulkefli, Voon \& Mahdi, 2020). As such, there are many socio-economic development processes and activities which will directly or indirectly affect the household happiness of the fast-developing suburb. Having a safe and healthy physical environment is always important. Physical facilities and service tangibles are essential to meet and exceed the individuals' and households' physical, emotional, and even spiritual needs and expectations for happiness. The servicescape attributes can affect people's well-being (e.g., Simpson, Siguaw \& Simpson, 2015). The socio-economic development environment and service tangibles include schools, shops, factories, hospitals, clinics, houses, offices, churches, temples, mosques, roads, bridges, buildings, and others.

\subsection{Methodology}

This paper aims to present the preliminary exploratory research findings for Batu Kawa suburban (Kuching, Sarawak) and the related personal experiences (first co-author) from Shaoxing (Zhejiang, China). The qualitative research for this Batu Kawa case study employed qualitative interviews and personal visits (by the lead author and second co-author). The qualitative exploration in Batu Kawa involved two group interviews to explore the sustainable suburban socio-economic service for household happiness. The interviewees were made up of twenty randomly selected representatives of the households who resided in the suburban. They were of different races (e.g., 12 Chinese, 4 Malays, 2 lbans, and 2 Bidayuhs), age groups, and occupations. The interviews were conducted online via Google Meet and WhatsApp. The major questions used in the interviews were: Are you happy staying in Batu Kawa and why?; What are the challenges/problems faced?; Do you think you have a happy household and why do you say so?; How can your household be happier?; and What can you do to make your household happier? The data collected from the qualitative interviews were content analyzed and numerous socio-economic service dimensions/items were identified. Besides, the researchers also went to the suburban areas to personally see, understand, and experience the socio-economic development, and environment service rendered there. Many relevant 
pictures were taken to support and illustrate the sustainable socio-economic development service rendered to the households in Batu Kawa (Malaysia). The co-author in Shaoxing (China) documented her personal experiences and observations about suburbanization. The related pictures were taken to share the sustainable socio-economic environment and service for household happiness, from her perspective.

\subsection{Findings and Discussions}

\subsection{Batu Kawa (Sarawak, Malaysia)}

Batu Kawa suburban, located about 5-20 kilometers from Kuching City, is a harmonious, multi-racial settlement area. The relatively more comprehensive and balanced socio-economic development agendas of Batu Kawa have been receiving good attention and support from the governments, private enterprises, and non-governmental organizations (NGOs) for even more vibrant growth and prosperity (see Figure 1) to serve the households.

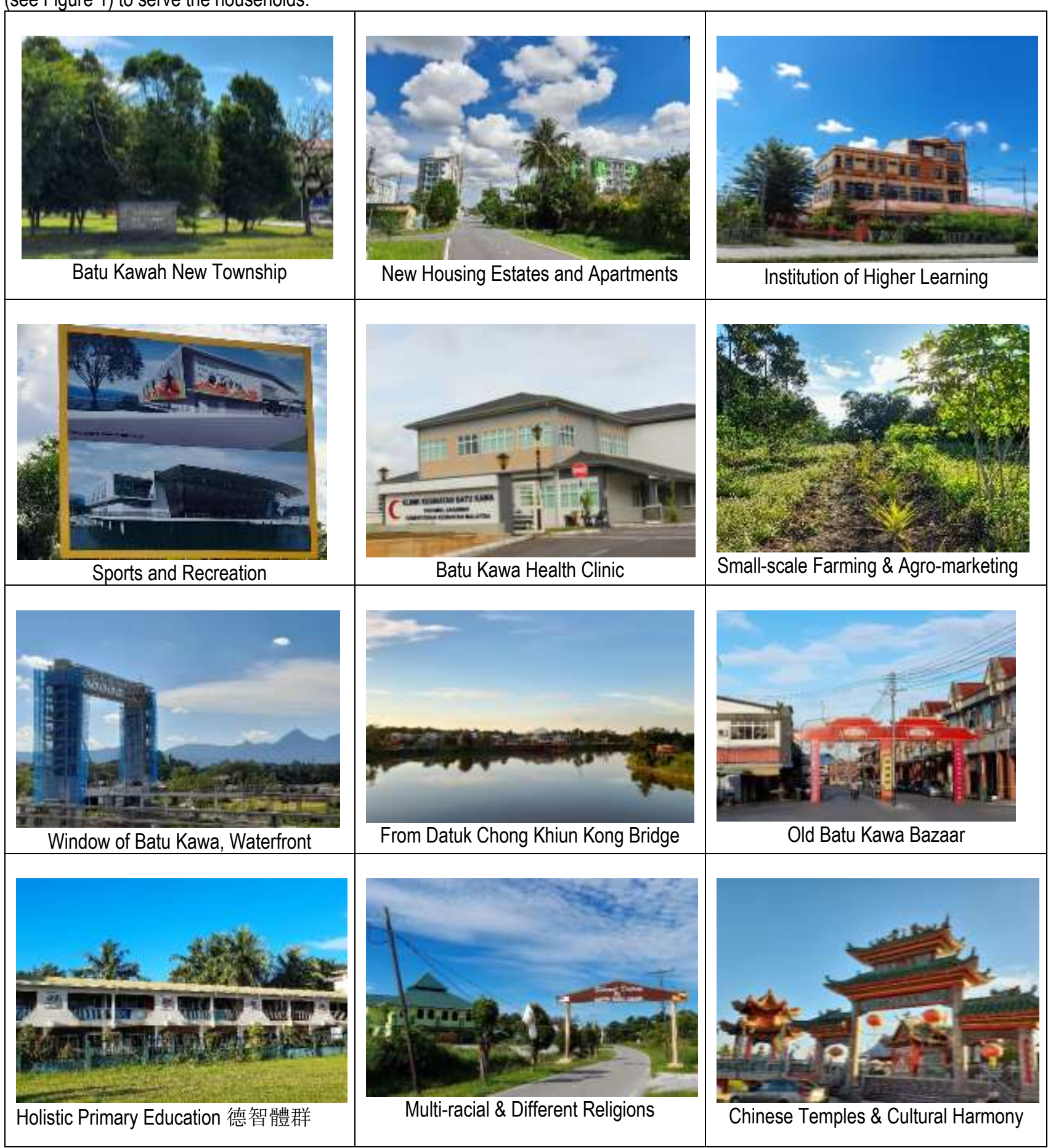

Figure 1. Socio-economic Development Environment and Service in Batu Kawa Suburban 
This periphery municipal area is administered and managed by Kuching South City Council and Padawan Municipal Council respectively. The early settlement started mainly nearby the old Batu Kawa town. This beautiful sub-urban or sub-rural area (after the Datuk Chong Kiun Kong Bridge) consists of 10 roads, 10 Chung Hua primary schools, has more than 5000 households. It is mainly settled by the Chinese Hakkas (now with different Chinese clans), and Malays, and has undergone fast economic development after the bridge was built in the early 1990s. For the past 10 years, there have been many housing development projects in this suburb and there are many households with diverse ethnic cultures and faiths now. There are also many Bidayuh and Iban families residing here and more government schools, and an institute of higher learning. The occupations of the residents here include construction workers, clerks, technicians, salesmen, government servants, and others. Many of them are businessmen in the retailing sub-sector. There is a big government health clinic (near MJC, Stapok), and other small-sized clinics.

The old Batu Kawa Bazaar has 61 shops, 38 nearby the Bridge, and about 200 units of relatively new shop-houses at Sungai Moyan Junction and along the Pan Borneo Highway towards Musi. There are more and more commercial shophouses, light industrial establishments, and new housing projects. The fast and vibrant socio-economic development can be observed. This is the service to the Batu Kawa people. The service tangibles include infrastructural facilities, sports and recreational, basic utilities, ICT facilities, moral and spiritual establishments, and sincere acts of service by the relevant stakeholders. The new development projects such as Batu Kawa Riverside Park, Sports and Recreational Hub, and MJC New Township are well-planned to meet the environmental, and safety requirements.

In the qualitative interviews, the respondents revealed that the reasons for being happy staying in Batu Kawa are as follows:

1. Comfortable living here

2. It is near to the city

3. Multiracial neighborhood and they are friendly

4. My family members are staying in Batu Kawa.

5. Convenient

6. Schools are nearby

7. The housing area is quiet and calm

8. Can do physical exercise easily

9. Feel safe

10. Easily can get groceries

11. A strategic place

12. Staying there for a long time

13. The market is accessible and can get many local foods

14. Near to facilities such as hospitals, shopping malls, and others

15. Near to sources of income/workplace

16. Rapid development

17. Near to the market, Kuching city mall

18. Problems such as road damages are promptly solved

19. Live harmoniously and people are friendly

20. Many opportunities in business

They are satisfied staying in this suburb mainly due to its proximity to Kuching City and the various facilities that they need in their daily lives, the harmonious living environment and friendly people, safety and security, facilities for healthy living (e.g., parks) are available, multi-racial community, and good housing and services. Nevertheless, the suburban households are also experiencing many socio-economic challenges such as relatively low disposal household income, less income-generating economic activities, the elderly groups' dependence on children for socio-economic well-being, relatively lower quality of personal health, need for more opportunities for higher education, diminishing land ownerships, poor public transport service (e.g., traffic jams), unstable household happiness, and need for continual political supports. The overall quality of life of the households is improving.

The households' adaptive attitudes and initiatives are exemplary and recommendable. The various socio-economic development initiatives and services for sustainability are potential for others to emulate for sustainable suburban development.

\subsection{Shaoxing (Zhejiang Province, China)}

The followings are the useful insights, personal observations and experiences of the first co-author (Wang) in Shaoxing, for possible consideration of sustainable suburban socio-economic development:

\subsubsection{Nature}

Shaoxing is one of the 10 cities in China that is considered the fittest for living. Nature is one important part that contributes to this honor. As a water city, the natural scene is the pride of Shaoxing. The government of Shaoxing has devoted a lot to preserve its beauty. It is exaggerated but somewhat true that once an individual steps out of the house, he/she steps into a park (see Figure 2). Quite many residents prefer life in the medium-sized city of Shaoxing. 


\subsubsection{Leisure}

Nowadays, people pay more attention to the body health aspect. Square dancing is popular in China. In Shaoxing, apart from square dancing, people enjoy a stroll if there's a footpath nearby. On weekends or during holidays, hiking is a favorite activity. Friends and relatives call each other and climb a mountain together. They would have a picnic on the mountain or dine together in a restaurant after climbing. It's a good way to promote intimacy and health. There are many punch spots. For example, Fuzhishan golden cole flowers and Wanweishan cherry blossom in spring, Ten Mile Lotus Pond in summer, golden ginkgo leaves in parks, and Xuedou Ridge redwood in autumn. The variety of scenery adds to the colorful life of citizens. Nature and leisure are essential for household happiness.

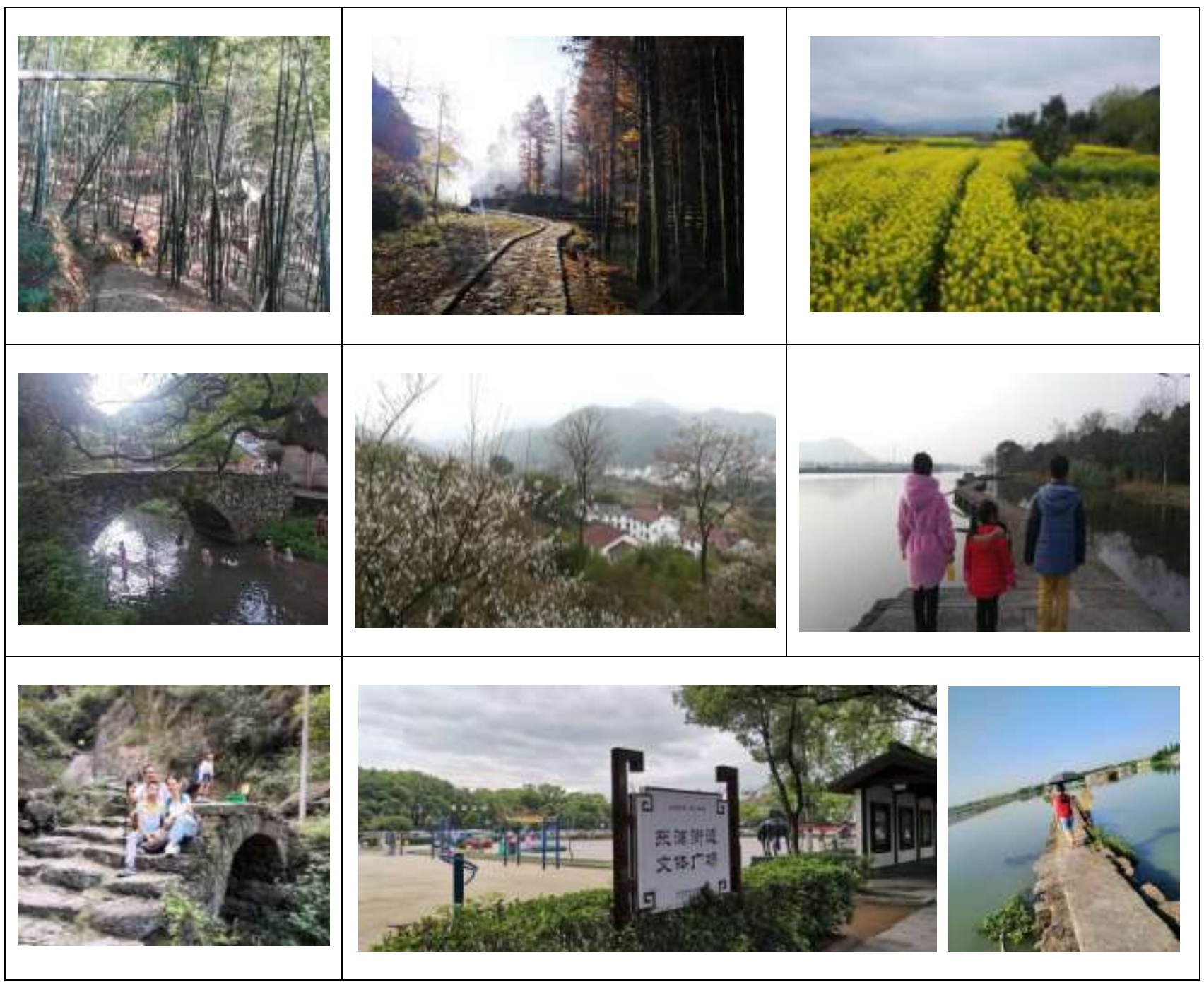

Figure 2. Nature, Leisure and Recreation in Shaoxing

\subsubsection{Culture}

Shaoxing is a well-known ancient city. It gains fame not only from natural heritage but also from plenty of cultural heritage. Till now, it has obtained 26 items of state-level intangible cultural heritage and 86 of provincial level. A series of promotional events was launched by the local government around Cultural and Natural Heritage Day. Exhibitions or performances are held free in almost every county's cultural center, even in some village cultural centers which greatly promote the quality of suburban cultural life. There are 186 suburban cultural centers in the Keqiao District at the end of 2020 (statistics from the website of Shaoxing Keqiao Center for Disease Prevention and Control).

\subsubsection{Infrastructural Facilities}

Roads are imperative for the in-situ socio-economic development of the targeted geographical area. There is a saying that: "Want to get rich? Build roads first." A total of about 30 projects in Shaoxing City are included in the provincial comprehensive transportation investment plan for the Year 2021. This huge investment (more than 20 billion yuan) is community-driven and it is a long-term service for the welfare of the people. These projects mainly involve seven fields: railway, urban rail transit, expressway, general national highway, rural highway, integrated passenger transport hub, and water transportation. The distance between the suburb and city center is shorter 
with a strong transportation system. Every village could be reached through public buses. Passengers can see when the bus will arrive or how far the bus is from the current stop on the electronic screen or by scanning a QR code. Usually, there is still some distance away from the bus stop to the destination. Public bicycles, free for one or two hours, could be seen near many bus stops.

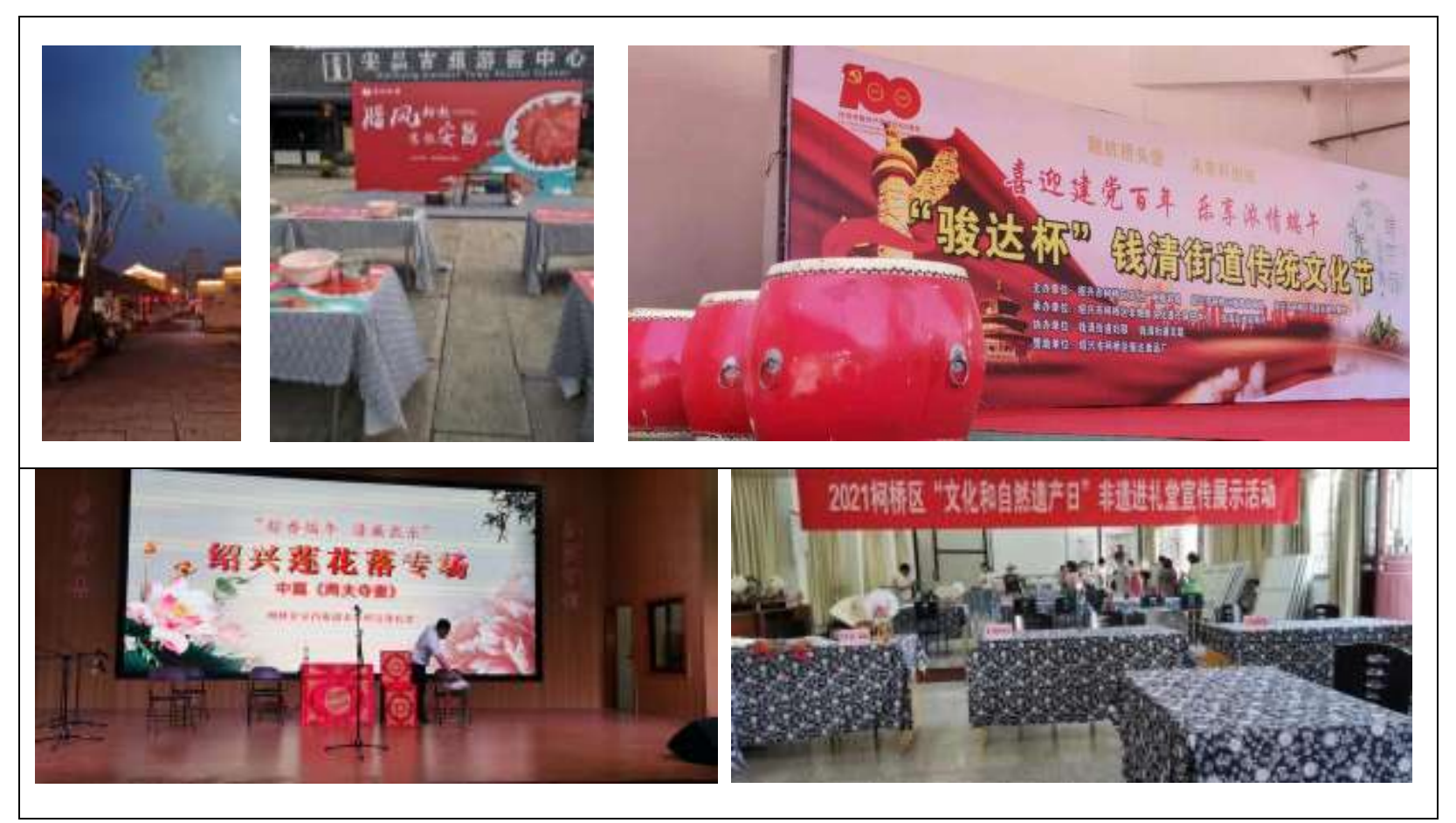

Figure 3. Cultural Activities and Promotions

\subsubsection{Health}
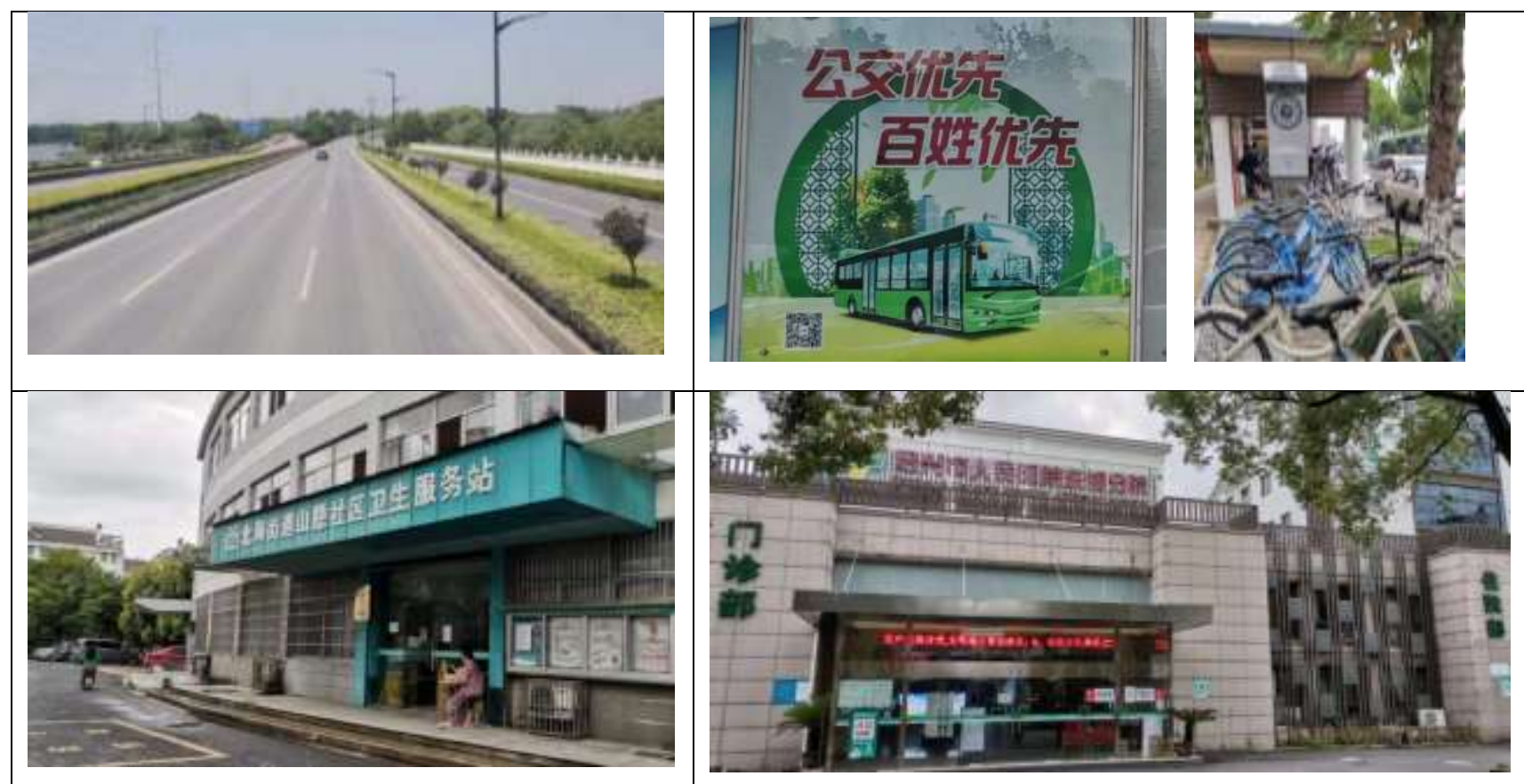

Figure 4. Infrastructural, Public Transportation and Healthcare Services

Rural cooperative medical security, funded by individual contributions and local/central governments, covers major diseases to reduce the burden of farmers and benefit the people. The standard of contribution for farmers in 2020 was 280 yuan per person per year and the period of entitlement is in 2021. The security includes general outpatient treatment and hospital basic medical treatment. Reimbursement rates vary according to different levels of hospitals and treatment costs. Pictures below show the community medical treatment spot and a hospital in Dongpu Town, Keqiao District (see Figure 4). Nearly 90\% of the town-level hospitals in Shaoxing City 
can provide inpatient services and all of them can carry out night outpatient and emergency services, outpatient surgery, an electronic push of inspection reports, and so on. It is very convenient for patients to receive inspection reports on their Smartphones.

\subsection{Discussion}

Sustainable suburban socio-economic development requires comprehensive coverage and systematic processes. Having an exact boundary of a suburb and its administrative jurisdiction for effective maintenance and monitoring purposes is challenging. A detailed geographical map is essential. Besides, a valid and reliable measurement for the socio-economic development service is necessary for effective performance management. The qualitative interviews and visits suggest that the governments' efforts, initiatives and cooperations among the public and private entities, attitudes and behaviors of the households could affect the household happiness. The various SDGs need to be emphasized and achieved accordingly.

The continuous and consistent socio-economic service from the governments (federal, state, and local levels) and concerted efforts from all stakeholders are necessary. These are essential for a comprehensive and inclusive sustainable socio-economic development amidst the various unavoidable challenges such as the COVID-19 pandemic. The evolving needs and wants of the household have to be understood. Relevant lessons can be learned from good suburbanization cases. For example, the insights from Shaoxing in terms of public health, transportation, nature and recreations, cultural preservation are useful. Relevant research and sustainable suburban development information system need to be developed, implemented, and monitored. Public-private-household engagements are instrumental in achieving and sustaining the desired socio-economic development.

\subsection{Conclusion \& Recommendations}

The findings from this qualitative exploratory research suggest that the study area, Batu Kawa suburban in Kuching, is experiencing satisfactory sustainable socio-economic development and there were numerous dimensions of sustainable suburban development that would affect the household happiness. The suburban environment and service were found to be household-oriented for their better quality of life. Among the limitations of this exploratory research are the representativeness of the empirical data due to the COVID-19 pandemic as well as the unavailability of data using face-to-face interactions. Besides, the representative quantitative data will be necessary for more conclusive data analysis to validly identify the sustainable socio-economic development service dimensions and items. The measurement for household happiness also will need the quantitative questionnaire survey data. The causal relationships among the development service dimensions and household happiness will also be investigated quantitatively for more conclusive information.

\section{Acknowledgment}

We thank UiTM Cawangan Sarawak and Universiti Teknologi MARA for providing financial support under the SDG Borneo Research Grant 600-RMC/SDG-Borneo 5/3 (011/2020). Thanks to Grace Phang Ing, Abang Azlan Muhamad, Vloreen Nity Mathew, and Kelvin T. H. Goh. The kind assistance from Padawan Municipal Council and SUPP Batu Kawa Service Centre, all interviewees, and assistants who have helped in the data collection processes are much appreciated. All pictures presented in this paper were taken by the authors (i.e., pictures in Batu Kawa by Boo Ho Voon, Shaoxing by Liping Wang).

\section{Paper Contribution to Related Field of Study}

This paper contributes to the theory and practice of sustainable socio-economic development and service for suburbanization in the field of development economics and service management. The environmental and behavioral insights from Batu Kawa (Sarawak, Malaysia) suburban development and lessons learned from Shaoxing (Zhejiang, China) are most probably good for balanced and sustainable socio-economic development and service for suburbanization. These qualitative inputs are also useful for the next phase of quantitative research using questionnaire survey to develop the sustainable suburban socio-economic service model.

\section{References}

Abu Bakar, A. H., Cheen, K. S., \& Rahmanwaty (2011). Sustainable Housing Practices in Malaysian Housing Development: Towards Establishing Sustainability Index. International Journal of Technology, 2, 83-92.

Chen, X., Luo, J., Wang, X., \& Yang, D. (2020). Supply chain risk management considering put options and service level constraints. Computers \& Industrial Engineering, 140 (2020) 106228. https://doi.org/10.1016/j.cie.2019.106228

Hezri, A. A. (2004). Sustainability indicator system and policy processes in Malaysia: A framework for utilization and learning. Journal of Environmental Management, 73, 357-371. DOI: 10.1016/j.jenvman.2004.07.010

Fan, T. \& Xue, D. Q. (2018). Sustainable Development of Cultural Industry in Shaanxi Province of Northwest China: A SWOT and AHP Analysis. Sustainability, 10, 2830; DOI: $10.3390 /$ su10082830 
Freimane, A. (2021). Perceived Design Value: The Socio-economic Impact of Design. Art Academy of Latvia, Latvia.

Jang, W., Yuan, F., \& Lopez, J. J. (2021).Investigating sustainable commuting patterns by socio-economic factors. Sustainability, 13, 2180. https://doi.org/10.3390/su13042180

Péter, K. P., \& Csaba, L. (2021). New Ways of Thinking in Economics in the Service of a Sustainable Socio-economic Development. In book: Strategies for Sustainable Socio-economic Development and Mechanisms their Implementation in the Global Dimension. (Collective monograph), Publisher: VUZF Publishing House "St. Grigorii Bogoslov" Sofia.

Sachs, J. D., Kroll, C., Lafortune, G., Fuller, G., \& Woelm, F. (2021). Sustainable Development Report 2021: The Decade of Action of the Sustainable Development Goals Include the SDG Index and Dashboards. Cambridge: Cambridge University Press.

Sachs, J. D., Schmidt-Traub, G., Kroll, C., Lafortune, G., Fuller, G., \& Woelm, F. (2020). The Sustainable Development Goals and COVID-19: Sustainable Development Report 2020. Cambridge: Cambridge University Press.

Simpson, Sigauw, \& Sheng (2015). Tourists' Life Satisfaction at Home and Away: A Tale of Two Cities. Journal of Travel Research, 55(2), 1-15.

Twelfth Malaysian Plan 2021-2025. http://rmke12.epu.gov.my/about-us

Vargo, S.L., Wieland, H., \& Akaka, M.A. (2016). Innovation in Service Ecosystems. Journal of Serviceology, 1(1), 1-5.

Voon, B. H. (2012). Role of Service Environment for Restaurants: The Youth Customers' Perspective. Procedia - Social and Behavioral Sciences, 38,388 - 395. doi: 10.1016/j.sbspro.2012.03.361

Voon, B. H. (2018). Measuring service excellence attitudes for happiness and sustainability. Proceedings of $8^{\text {th }}$ International Conference on Gross National Happiness, 14-16 Nov 2018, UiTM Shah Alam, Malaysia.

Wang, L., Hu, M., Guo, Z. Sun, P., Geng, F., \& Voon, B.H. (2019). China Tourists' Experiences with Longhouse Homestays in Sarawak. Journal of Service Management and Sustainability, 4(2), 25-50.

Zulkefli, A.R, Voon, B.H., \& Rasidah Mahdi (2020). The Impact of Service Quality on Business Commitment in Contract Manufacturing Services: An Exploratory Study of F\&B Industry in Malaysia. International Journal of Business and Society, 20(1), 197-216. 